\title{
Anarchy and Autarky: Endogenous Predation as a Barrier to Trade
}

\author{
James E. Anderson \\ Boston College and NBER \\ james.anderson@bc.edu
}

\author{
Douglas Marcouiller \\ Boston College and NBER \\ douglas.marcouiller@bc.edu
}

September 30, 2001

\begin{abstract}
This paper presents a general equilibrium two-country Ricardian trade model with endogenous transactions costs arising from predation on trade. Agents rationally choose between predation and specialized production. Endogenously-generated insecurity dramatically reduces trade volumes. In the absence of institutions for risk-sharing and coordination of defense, autarky obtains over most of the parameter space. The model provides an excellent framework for understanding the historical collapse of trade between Spain and its American colonies and may also apply to contemporary instances of a collapse in security.

We thank participants in seminars organized by the Latin American and Caribbean Economics Association, the London School of Economics, Ludwig Maximilian University, the Midwest International Economics Working Group, the National Bureau of Economic Research, Notre Dame University, Pompeu Fabra University, and the University of Konstanz. Anderson acknowledges the hospitality and support of the NBER and the Institute for International Economic Studies, Stockholm, during work on this paper.
\end{abstract}


Recent empirical work throws up the shadow of huge transactions costs in international trade (summarized in Rodrik, 2000; see also Trefler, 1995). Modelers usually brush transactions costs aside, treating them as exogenous "iceberg-melting" costs or suppressing them entirely. This paper brings them front and center.

We focus on transactions costs arising from the exposure of international shipments to misappropriation. Empirically, it is clear that extortion, hijacking and theft dramatically reduce trade (Anderson and Marcouiller, forthcoming; Marcouiller 2001). Insecurity of this type is historically significant and also poses interesting challenges for model building. Unlike exogenous "iceberg melting" costs, the costs associated with predatory activity depend on the endogenous allocation of labor to predation, which in turns depends on the volume of trade. Under what conditions can endogenous transactions costs destroy trade? In an environment where predators must have prey to feed upon, can endogenous insecurity explain autarky?

We explore endogenous insecurity in a two-good, two-country Ricardian model. Agents will specialize and trade if the productivity-based gains from trade cover trade costs, including some fixed start-up costs. Trade costs also include possible capture of the shipment by thieves. The endogenously determined probability of eluding capture depends in part on the number of agents who forego productive activity to specialize in predation, a decision which, in turn, depends upon the volume and value of international shipments.

Trivially, autarky is always a Nash equilibrium of the model; no agent will choose to be the only producer undertaking the fixed costs of trade. The surprising result of our paper is that, for many parameter values, autarky is the only equilibrium; the mere possibility of predation is often enough to destroy trade. In numerical simulation of a Cobb-Douglas version of the model, four parameters prove to be critical to the existence of a trading 
equilibrium: the extent of fixed costs of trade, the relative effectiveness of predatory and evasive resources, the difference in autarky relative prices, and relative country size.

We have also found a novel result in the range of parameters which do support both predation and trade in equilibrium. Intuition suggests that, by encouraging specialization and trade, an improvement in evasion technology would always enhance welfare. However, the terms of trade of the larger country deteriorate with an increase in the volume of trade. Moreover, as security rises, former predators will return to production, and the terms of trade of their home country will also deteriorate (or deteriorate further). If the terms of trade effects are large enough, enhanced security will diminish welfare in one of the countries and perhaps even cause that country to abandon trade, thereby leaving both countries worse off. The paradox that predation may create trade and enhance welfare will be explored in detail.

To keep the focus on the fundamentals of predation, we have abstracted from organized crime and from organized risk-sharing through insurance markets. This is what we mean by "anarchy" - that neither predators nor producers organize for collective action. By showing how difficult trade is under anarchy, we implicitly underscore the importance of institutional development for the success of international markets.

This paper is related to the literature on predation (Anderton, Anderton, and Carter 1999; Grossman and Kim 1995; Skaperdas and Syropoulos 1996, 1997, and 2001) as well as to the literature on various sorts of trade costs (Deardorff 2001; Hummels 2001; Rauch 1999; Rauch and Trindade 1999). As far as we know, this is the first paper to offer a general equilibrium model with endogenous predation on trade. The interaction of predator and prey in our market model is anonymous, in contrast to the bilateral interaction of the earlier predation literature.

Section 1 motivates our model with a famous trade crash, the $17^{\text {th }}$ century collapse of Spain's Atlantic bullion trade. Sections 2 and 3 set up the model and show just how insecurity reduces trade in our model, and how 
parametric changes in insecurity affect the terms of trade. Section 4 completes the model with endogenous predation. Section 5 presents numerical simulations of the full model. Section 6 concludes.

\section{The Collapse of the Spanish Transatlantic Trade}

Before setting out our formal model, we would like to tell the tale of the dramatic collapse of trade between Spain and its American colonies. Some of the elements of this story have made their way into our much starker model of predation and (no) trade under anarchy.

The sixteenth century Spanish-American trade was so important that "all of European life and the life of the entire world. . could be said to have depended " on it (Wallerstein 1974 p.165, quoting Chaunu 1959). Why did it collapse? In the early seventeenth century, Spain's trading institutions proved ineffective in the face of a change in predatory technology. The system of annual fleets sailing under military escort had become both ineffective and prohibitively expensive. Nonetheless, the Spanish Crown, acting in support of the monopoly of Seville, continued to harass independent shippers by seizing cargoes and refusing to enforce insurance contracts. Spanish traders fell into something approaching our model's autarkic equilibrium under anarchy, with ineffective social institutions for risk-sharing and coordination.

Although smuggling complicates the interpretation of official statistics, it seems certain that trade between Spain and America shrank dramatically after 1625. Figure 1 displays the decline in the number of ships sailing westward each year. "From 1623 the trend was sharply and irretrievably downwards, both in prices and in the volume and value of trade. The great depression had begun, and it continued until, by 1650, the American trade in its classical form and dimensions was almost totally destroyed" (Lynch 1969, vol. 2, p. 188).

Several hypotheses have been proposed to explain the decline (Phillips 
1990, pp.85-87). Silver output in Mexico and Peru may have suffered from demographic changes in the labor force or a shortfall in supply of mercury, which was used in the amalgamation process. Problems with Spanish agriculture may have slowed the pace of domestic economic activity within Spain and thus the pace of Spanish trade. Diversification of local production may have mitigated the colonies' dependence on transatlantic trade. We argue that changes in the security of shipping played the critical role in the decline in trade, in turn impeding the supply of imported mercury and encouraging import-substituting production.

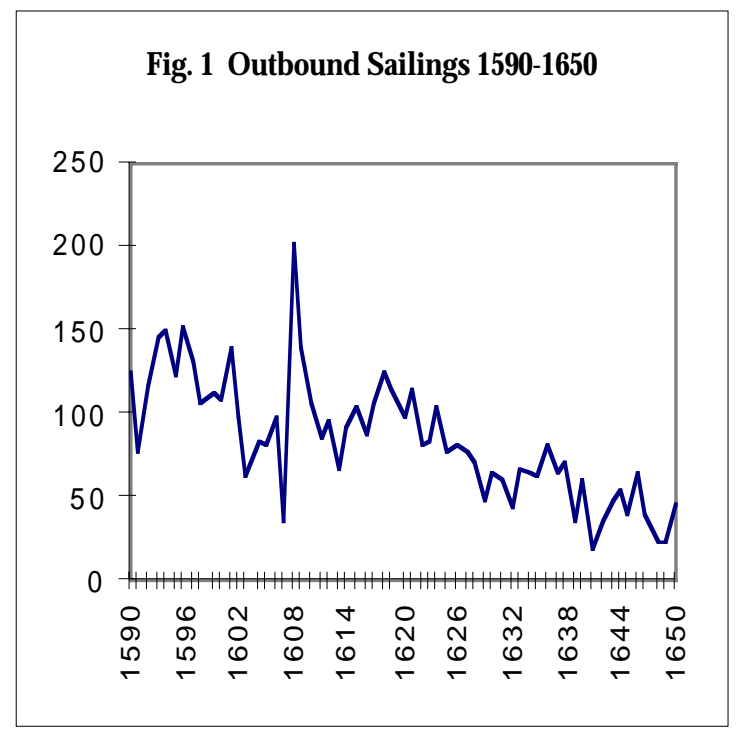

1: Based on Chaunu and Chaunu 1956, VI:1 329-330.

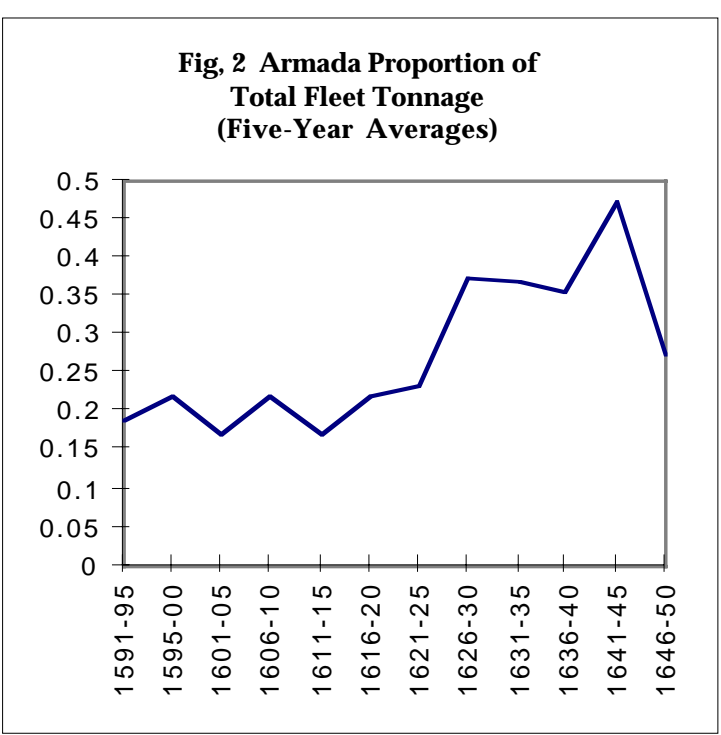

2: Based on Chaunu and Chaunu, VI:1 392-393.

Most of Spain's trade with America -- 85\% at the beginning of the seventeenth century (Phillips, p. 78) -- was carried on ships sailing in convoys organized by the official Casa de Contratacion in conjunction with the Consulado of Seville, the merchants' guild to which monopoly trading rights had been granted by royal charter. Mechner (1997) argues that these convoys were critical for the enforcement of monopoly rights and the extraction of monopoly rents; the threat of piracy was serious enough and the defensive convoys valuable enough to draw traders into compliance with the law and with the regulations of the Casa and the Consulado.

The system worked well from 1550 to 1620 . In 1621, however, the formation of the Dutch West India Company pushed past alliances of 
merchant and military capital to new heights, culminating in Piet Heyn's capture of nearly the entire fleet in 1628 (MacLeod, p.377). "Apart from the loss of vessels and the grievous loss of seamen, the trade was also deprived of almost a year's returns from New Spain, estimated at 36 to 40 percent of its working capital" (Lynch, p.190). This illustrated to all that large convoys were no longer impervious to coordinated attack; privateers no longer focused their attention primarily on individual ships which had fallen behind the rest of the fleet.

As Figure 2 shows, this debacle was followed by a dramatic increase in the proportion of the tonnage of each fleet devoted to the escorting armadas. The cost of these armed escorts was defrayed by the avería, a charge on shipments administered by the Consulado itself from 1562 until 1641 (Lynch, p. 163). The charge, which had stood at $7 \%$ of the value of shipments early in the seventeenth century, rose to $17 \%$ in 1629 and to 31.5\% in 1630 (Ward 1993, pp. 25-26). We have no comparable figures for insurance margins but can only assume that they also increased to reflect the changed nature of risk; shipping losses were no longer independent events. Figure 1 shows that the combined effect of higher margins was to destroy the official trade.

The efficient response of rational agents to the increased convoy charges would be twofold: smuggling and independent shipping. Smuggling, specifically the under-reporting of cargo actually shipped with the convoys, certainly did occur. This "was described as early as 1634 in an unpublished Royal Order of 18 March, which stated that the king and a few others who could not evade registration had to bear a disproportionate amount of the costs of the convoy, adding that it was rumored that the previous convoy had carried more unregistered than registered bullion" (Barrett 1990, p.235). However, smuggling was also risky. Veitia's 1672 history of the trade regulations notes that smugglers risked forfeiture of their cargo and of their offices (e.g., pp.166-167 and 689 in the 1945 edition).

There is little evidence of an increase in independent shipping and a good deal of evidence that the Crown sought to impede its growth. The 
Crown, "in its straits for money," did grant in particular cases permission to sail alone (Haring 1918, p.213). However, the value of that permission is not entirely clear. Single vessels ("navios sueltos") seem to have been restricted to trade with minor ports. In fact, the major Porto Bello fair in Panama for trade with Peru only came into being when the fleet was in port. Moreover, it seems that registered ships sailing alone were required to pay the avería, just as if they enjoyed the protection of the escorts (Veitia, p.201). It is certainly the case that registered ships which sailed westward alone but later joined or even followed the convoy on the more dangerous return trip were required to pay the full, round-trip avería (Veitia, p.210). Unregistered ships sailing alone, on the other hand, would be penalized for smuggling if caught, and shippers were unable to enter legally-binding insurance contracts to protect unregistered cargo (Veitia, p.715). The expense of sailing alone with permission and the uninsurable risk of sailing alone without it may explain why the Chaunus found on average fewer than five ships sailing alone annually between 1621 and 1650 (Chaunu and Chaunu, VI:1, p. 408). As the effectiveness of predation rose, the convoy system, a cost-effective means of defense in an earlier period, proved ineffective. Risk-sharing institutions permitting independent shipping did not emerge, and the Spanish-American trade did in fact collapse.

Many elements of this story find a place in the stylized model presented in this paper:

a) a fixed element in cost of trade, analogous to the cost of adhering to the regulations of the Consulado;

b) changes in the relative effectiveness of resources of predator and prey, analogous to the "new and threatening departure" represented by the formation of the Dutch West India company (MacLeod, p.377);

c) a range of parameters for which predator weakness deters the emergence of predation in equilibrium, analogous to the heyday of the convoy system;

d) a range of parameters for which insecurity limits specialization according 
to comparative advantage and another range over which insecurity completely deters trade, analogous to the decline and fall of the SpanishAmerican trade;

e) and, finally, sensitivity of the equilibrium to institutional configurations such as the availability of insurance and controls on free-riding.

\section{The Decision to Trade}

Our model captures the interaction of anonymous agents who fall into two groups or countries characterized by differing relative labor productivities, as in a classical Ricardian trade model. Agents must decide whether to bear fixed costs associated with positioning themselves to be able to trade. Conditional on this decision, they allocate their remaining labor across productive and predatory activities.

Agents who choose to trade face the risk of anonymous predation loss of their merchandise to thieves -- on the way to and from the market. Shippers and bandits distribute themselves across trade routes in such a way that each shipper (bandit) faces the same probability of successful shipment (theft). Coupled with the absence of mechanisms for risk diversification, the possibility of losing shipments exposes the traders to consumption risk. Even risk neutral agents can be worse off with trade than under autarky.

To abstract from inessential complexities of a dynamic model, we treat the decision to incur the fixed cost of trade as taken simultaneously with the allocation of the remaining labor between production of the two goods. However, the logic of decision-making is easier to describe if we think of it in two stages.

In the first stage, agents wishing to trade in the second stage must devote a part of their labor endowment to fixed start-up costs --- hiring a ship, building warehouses and the like. Some part of the cost may improve the shipper's ability to evade predators (speed, concealment). Each individual devotes either nothing or the fixed share $\bar{l}$ of his unit labor endowment to 
the start-up costs. Those who have positioned themselves to be able to trade face three options at the second stage: they can devote their remaining $(1-\bar{l})$ units of labor to production and exchange goods internationally, they can fall back into autarkic production for their own use, or they can engage in predation on shipments undertaken by others. Those who have not borne the fixed start-up costs are not in a position to trade. Their options are limited to two: they can devote their unit of labor either to predation or to production for home use. Note that, while not having paid the startup costs rules out trade as a second-stage strategy for some players, those players remain free to choose in the second stage between autarkic production and predation.

Figure 3: Decisions of Agents in the Home Country

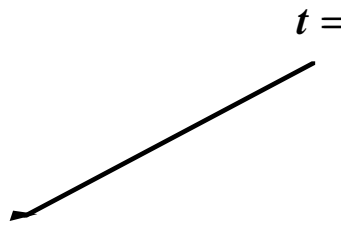

Pay Start-up Cost $\bar{l}>0$

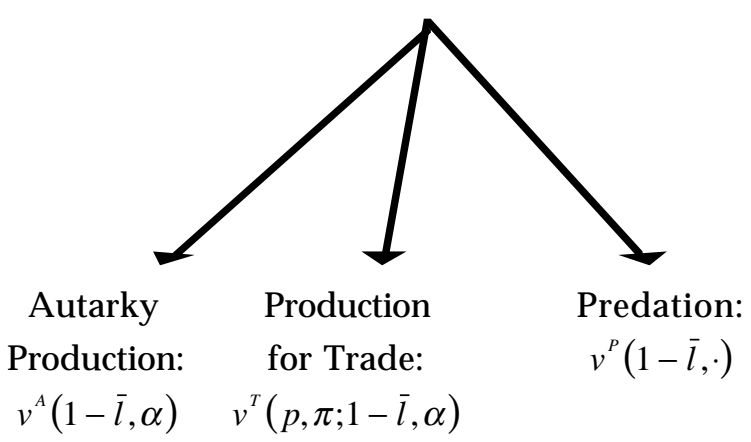$$
t=0
$$

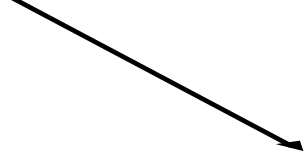

Do Not Pay Start-Up

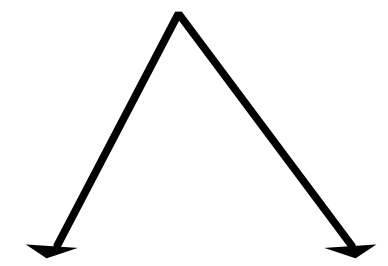

Autarky Predation:

Production: $\quad v^{P}(1, \cdot)$

$v^{A}(1, \alpha)$

Let $p$ be the relative price of good 1 , and let $\pi$ represent the probability that a shipment eludes capture by predators. The probability is exogenous to the individual trader due to our assumption of binary choice: either the potential trader pays the fixed cost or he cannot trade at all. He takes the market successful shipment rate as a parameter. Let $\alpha$ denote the exogenous opportunity cost of good 1 in terms of good 2 along the production frontier. The autarkic equilibrium indirect utility function of an agent in the home 
country is $v^{A}(1, \alpha)$, where the first argument denotes the unit of labor devoted to autarkic production. With trade, the home producer's indirect utility function is given by $v^{T}(p, \pi ; \bar{l}, \alpha)$. We derive these below on familiar lines. An agent who specializes in predation gains indirect utility $v^{P}(\cdot)$, which will be shown in Section 4 to be a function of the labor devoted to predation, the probability of capturing a shipment $(1-\pi)$, the terms of trade $p$, the number of competing predators, and the amount of specialized production on either side of the market.

Three types of Nash equilibrium are possible. Trivially, autarky is always a Nash equilibrium because if no one else is prepared to trade, an agent knows that he will have no partner and thus cannot benefit from incurring the fixed cost of trade. Two other Nash equilibria may emerge. A "secure equilibrium" is one in which all agents bear the start-up costs and trade. An "insecure equilibrium" is one in which some agents bear the start up costs and trade, while others opt for predation on that trade. The key result of our paper is that autarky is the only equilibrium for most parameter values.

Autarky could be the only equilibrium for two reasons - one familiar, the other novel. The familiar reason is that the exogenously fixed start-up costs of trade are high enough to wash out the potential gains from trade. The more novel cause of a unique autarky equilibrium is that, although gains would be possible if no predators entered, once trade starts up the entry of predators leads to terms of trade and a level of insecurity inconsistent with gains from trade for agents in one of the countries. Let $p^{0}, \pi^{0}$ denote the price and success rates associated with equilibrium defined exclusive of the entry condition. Then there is no trading equilibrium if $v^{A}(1, \alpha)>v^{T}\left(p^{0}, \pi^{0} ; 1-\bar{l}, \alpha\right)$, so that home agents are unwilling to trade, or $v^{A^{*}}\left(1, \alpha^{*}\right)>v^{T^{*}}\left(p^{0}, \pi^{0} ; 1-\bar{l}^{*}, \alpha^{*}\right)$, so that foreign agents are unwilling to trade.

The second possible equilibrium is characterized by perfectly secure trade. All agents bear the start-up costs and then trade; no one opts for 
predation on the trade. Let $p^{e}$ denote the secure equilibrium price. Entry into trade requires that $v^{T}\left(p^{e}, 1 ; 1-\bar{l}, \alpha\right)>v^{A}(1, \alpha), v^{T^{*}}\left(p^{e}, 1 ; 1-\bar{l}^{*}, \alpha^{*}\right)>v^{A^{*}}\left(1, \alpha^{*}\right)$, $v^{T}\left(p^{e}, 1 ; 1-\bar{l}, \alpha\right)>v^{P}(\cdot)$, and $v^{T^{*}}\left(p^{e}, 1 ; 1-\bar{l}^{*}, \alpha^{*}\right)>v^{P}(\cdot)$. Not only must there be significant gains from trade, but the gains from predation must be small. What is required for this to occur will be easier to explain once the $v^{P}$ function has been fully delineated.

Finally, an insecure equilibrium is one in which some agents in each country bear the start-up costs and trade while others opt for predation. This requires that $v^{T}\left(p^{e}, \pi ; 1-\bar{l}, \alpha\right)>v^{A}(1, \alpha)$ and $v^{T^{*}}\left(p^{e}, \pi ; 1-\bar{l}^{*}, \alpha^{*}\right)>v^{A^{*}}\left(1, \alpha^{*}\right)$. It also requires that $v^{T}\left(p^{e}, \pi ; 1-\bar{l}, \alpha\right)=v^{P}(\cdot)$ and $/$ or $v^{T^{*}}\left(p^{e}, \pi ; 1-\bar{l}^{*}, \alpha^{*}\right)=v^{P^{*}}(\cdot)$. Predation is a free entry activity, and $v^{P}$ is declining in the number of predators. Agents from the country with the lower utility will enter predation until the marginal agent is indifferent between predation and production for trade.

Note that some decisions can be ruled out. In equilibrium, no one who chooses to bear the start up costs of trade will fail to trade in the second stage. Bearing $\bar{l}$ but subsequently shifting to autarky is a dominated strategy, since $v^{A}(1, \alpha)>v^{A}(1-\bar{l}, \alpha)$. Similarly, since $v^{P}(1, \cdot)>v^{P}(1-\bar{l}, \cdot)$, bearing $\bar{l}$ but subsequently shifting to banditry is dominated.

If in equilibrium anyone pays $\bar{l}$, no one will opt for autarky. All agents within a country are identical; if trading utility dominates autarky utility for any agent in a country, it must dominate autarky utility for all agents in that country. Furthermore, in equilibrium no one will pay $\bar{l}$ unless trade can actually take place, which requires that utility under trade dominate autarky utility for agents in both countries. Therefore, in equilibrium anyone who pays the startup costs of trade will trade, and if any agent pays the startup costs, all agents will either trade or prey upon the trade. Consequently, in equilibrium, if some agents pay $\bar{l}$ and others do not, those who have not paid $\bar{l}$ will choose predation in the second stage. Due to this structure, the decision to commit the trade cost is also in equilibrium a career choice 
between predation and specialized production for trade.

\section{Production and Trade with Fixed Numbers of Producers and Predators}

Those agents who have incurred the fixed startup cost of trade allocate their remaining labor between the two goods. Predation exposes the agents to consumption risk, so that we need not expect complete specialization as in the classical Ricardian model. Trade volume is an increasing function of the expected success in shipment and of the anticipated terms of trade under conditions provided below. The agents interact in an international market subject to predation, and it is very helpful to initially analyze the determination of the terms of trade with given numbers of specialized producers and predators.

\section{The Trader's Output and Trade Choices}

Let $\left(y_{1}, y_{2}\right)$ be the production levels of the two goods. The constant opportunity cost of producing good 1 is higher at home than abroad, and, to economize on notation, we assume that the unit labor requirement in the export good is equal to 1 . Given a decision to bear the fixed cost of entry into international exchange, $\bar{l}$, the Ricardian technology for each potential trader in the home economy is described by:

$$
\alpha y_{1}+y_{2} \leq 1-\bar{l}
$$

where $\alpha$ is the constant opportunity cost of the import-competing good.

All agents share identical preferences. Each of the traders must choose the output of each good and the amount of each to offer for sale in the international market at price $p$ (the price of good 1 in terms of good 2). Agents trade only once each period. We thus rule out for simplicity any ex post trade within countries between successful and unsuccessful agents. The trade vector is $\left(m_{1}, m_{2}\right)$, where exports appear as negative quantities. 
Conditional on having undertaken the fixed start-up costs, the potential trader's problem is:

$$
\max _{y_{1}, y_{2}, m_{1}, m_{2}} \pi u\left(y_{1}+m_{1}, y_{2}+m_{2}\right)+(1-\pi) u\left[y_{1}+\min \left(m_{1}, 0\right), y_{2}+\min \left(m_{2}, 0\right)\right]
$$

subject to

$\alpha y_{1}+y_{2} \leq 1-\bar{l}$

$p m_{1}+m_{2} \leq 0$.

The agent maximizes the utility of consumption; in the event of predation, consumption is equal to the production level for the imported good and equal to the production level less the stolen exports for the exported good. The first constraint reflects the Ricardian technology for each potential trader in the home economy. The second is the balance of payments constraint. The maximum value function for this program yields the indirect utility function for traders, $v^{T}(p, \pi ; 1-\bar{l}, \alpha)$. A similar program for the foreign representative agent yields the foreign trade indirect utility function $v^{* T}\left(p, \pi ; 1-\bar{l}^{*}, \alpha^{*}\right)$.

The first order conditions of the maximization program reveal the characteristics of the choices which the agent will make. Let $u_{i} \equiv \partial u / \partial\left(y_{i}+m_{i}\right)$ denote the marginal utility of consumption of good $i$. Denote the marginal utilities when exchange is successful with a superscript G (Good state) and when exchange is unsuccessful with a superscript B (Bad state). Then

$$
\frac{\partial u^{B}}{\partial m_{i}}=\left\{\begin{array}{l}
u_{i}^{B} \text { for } m_{i}<0 \\
0 \text { for } m_{i}>0
\end{array}\right.
$$

The derivatives of utility with respect to trade are undefined at the autarky point, but, conditional on the agent's having committed the fixed cost of trade, it must be true that trade is sufficiently large for the gains from it to pay the fixed cost. Thus, conditional on the entry cost being rationally paid in equilibrium, we know the derivatives are defined. Just as in the standard model, the foreign exchange constraint will always bind. This follows from the first order conditions for trade:

$$
\begin{aligned}
& \pi u_{1}^{G}+(1-\pi) \partial u^{B} / \partial m_{1}=\pi u_{1}^{G} \leq \mu p \\
& \pi u_{2}^{G}+(1-\pi) u_{2}^{B} \leq \mu .
\end{aligned}
$$


Here, $\mu$ is the Lagrange multiplier for the foreign exchange constraint. If the constraint does not bind, $\mu=0$, but in this case the above first order conditions cannot be met because at least one of the expected marginal utilities must be positive for a sensible utility function.

In contrast to the standard Ricardian model, the amount of trade is reduced by incomplete specialization except for a limiting case identified below. The first order conditions in the trade vector imply:

$$
\frac{\pi u_{1}^{G}}{E\left[u_{2}\right]}=p
$$

where $E$ is the expectations operator such that $E\left[u_{2}\right] \equiv \pi u_{2}^{G}+(1-\pi) u_{2}^{B}$. Equation (3.3) can also be written as:

$$
\frac{u_{1}^{G}}{u_{2}^{G}}=p+p \frac{1-\pi}{\pi} \frac{u_{2}^{B}}{u_{2}^{G}} \text {. }
$$

The first order conditions in the output vector require the two conditions:

$$
\begin{aligned}
& \pi u_{1}^{G}+(1-\pi) u_{1}^{B}=\lambda \alpha \\
& \pi u_{2}^{G}+(1-\pi) u_{2}^{B}=\lambda
\end{aligned}
$$

where $\lambda$ is the Lagrange multiplier for the labor constraint. In the standard Ricardian model, one of these conditions usually does not bind, and hence, by complementary slackness, one of the outputs is equal to zero. Here, in contrast, both conditions will usually bind, implying incomplete specialization. Taking the ratio of the first equation to the second at an interior solution and using (3.3):

$$
\alpha=\frac{E\left[u_{1}\right]}{E\left[u_{2}\right]}=\frac{\pi u_{1}^{G}}{E\left[u_{2}\right]}+\frac{(1-\pi) u_{1}^{B}}{E\left[u_{2}\right]}=p+\frac{(1-\pi) u_{1}^{B}}{E\left[u_{2}\right]} .
$$

Thus, the interior solution involves a specialization in which the "marginal rate of expected substitution" is equal to the marginal rate of transformation $\alpha$, but both of these, along with the marginal rate of substitution in the good state, are greater than $p$.

Figure 4 depicts the agent's decision. Point $\mathrm{A}$ is available in autarky with utility $u^{A}$. Trade requires effort $\bar{l}$, shifting in the production 
possibilities frontier to the heavy line. The trader's optimal production bundle, Y, which no longer need be completely specialized, permits consumption at $\mathrm{G}$ if exchange succeeds. If exchange fails, consumption must fall to B. If exchange were secure, the agent would specialize completely in production of good 2 and would consume at E.

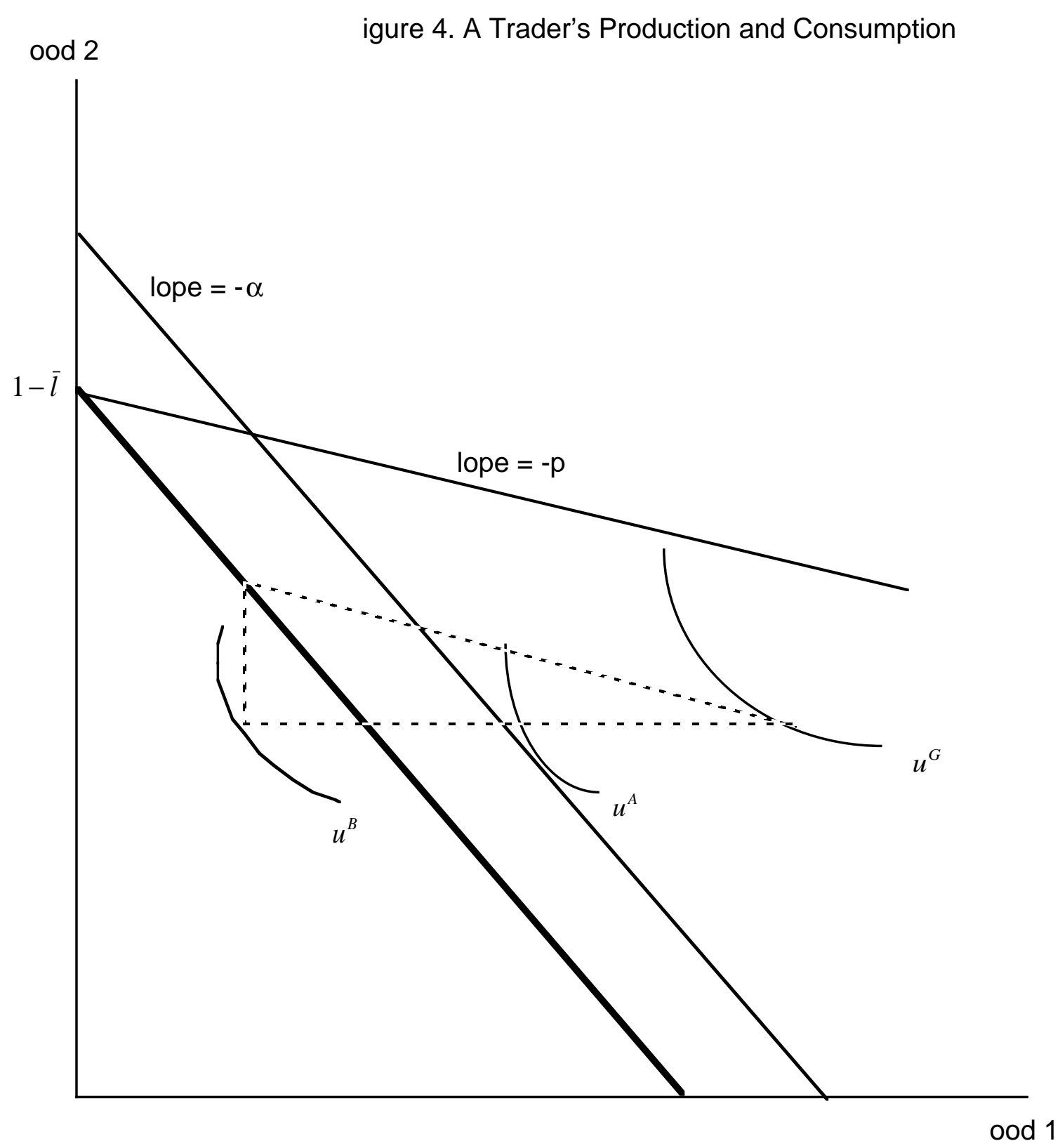

The system (3.3), (3.5) and the two constraints of the maximization program give four equations to determine the four variables $\left(y_{1}, y_{2}, m_{1}, m_{2}\right)$. 
With concave utility, the solution is globally unique. The output and trade variables are implicit functions of the exogenous (to the individual) variables $p$ and $\pi$ along with the parameters $\bar{l}$ and $\alpha$. Intuitively, we expect the volume of imports to be an increasing function of both security and the terms of trade (the inverse of the relative price of imports). Potential difficulties arise because of the nature of consumption risk in the model. A condition restricting preferences further is sufficient for the intuitive results:

Proposition 1: If preferences are such that goods are weak Pareto complements, $u_{12} \geq 0$, then

(a) import volume rises with the security of shipments $\pi$;

(b) import volume falls with its relative price.

Proof: At an interior solution the full employment and balance of trade constraints can be used to substitute in the utility function for $y_{2}, m_{2}$ in terms of $y_{1}, m_{1}$. We drop the commodity subscript for neatness. The agent's program in the region of parameter space where good 1 is imported is

$$
\max _{y, m} W(y, m ; \pi, p)=\pi u(y+m, 1-\bar{l}-\alpha y-p m)+(1-\pi) u(y, 1-\bar{l}-\alpha y-p m) .
$$

Let $\mathbf{H}(W)$ denote the negative definite second derivative (Hessian) matrix of $W$. Weak Pareto complementarity can be shown to imply that $W_{y m}=W_{m y}<0$ and $W_{y y}<W_{y m}$. Concavity at an interior optimum guarantees $W_{y y}<0, W_{m m}<0$, and $|\mathbf{H}|=W_{y y} W_{m m}-W_{y m}^{2}>0$. Trade responds to security improvements according to:

$$
\frac{d m}{d \pi}=-\frac{1}{|\mathbf{H}|}\left(W_{y y} W_{m \pi}-W_{y m} W_{y \pi}\right)
$$

which must be greater than zero, since it can be shown that $W_{m \pi}>0$ and $W_{y \pi}<0$. This proves (a). Trade responds to price according to:

$$
\frac{d m}{d p}=-\frac{1}{|\mathbf{H}|}\left(W_{y y} W_{m p}-W_{y m} W_{y p}\right) .
$$

It can be shown that $W_{m p}<W_{y p}<0$. Since under the Pareto complements 
condition $W_{y y}<W_{y m}<0$, it follows that $d m / d p<0$. This proves (b). ||

The Pareto complements condition is over-sufficient but simpler than any alternative restriction, while concavity alone does not suffice. (The reader may verify this by examining, for example, $W_{m y}$.) The Cobb-Douglas case used in our simulations satisfies the Pareto complements condition, as does the CES utility function.

As usual in trade models, export supply schedules can have a backward bending portion, while they must be upward sloping near the vertical axis. Export supply is increasing in security $\pi$. This follows from Proposition 1 and noting that when good 1 is imported, the exports of good 2 are equal to $p m_{1}$ and the slope of the export supply schedule is given by $d m_{2} / d(1 / p)=-p^{2}\left[m_{1}+p d m_{1} / d p\right]$.

Greater aversion to income risk (imposed by strictly concave transformations of utility) reduces trade. An infinitely risk averse agent (who maximizes his minimum utility) will stay at autarky no matter how favorable the price; otherwise it pays to accept some trade, given the initial commitment of fixed cost. Low elasticity of substitution between goods makes consumption risk more painful and thus reduces trade more. Indifference to consumption risk requires both straight line isoutility loci (infinite elasticity of substitution between goods) and income risk neutrality, otherwise trade is reduced by the risk of theft. Finally, generalizing production to include diminishing returns weakens forces of specialization as in perfectly secure trade models but retains the property that trade is reduced by insecurity.

Several general points should already be clear. First, insecurity reduces trade. Second, despite Ricardian technologies, producers may not completely specialize according to comparative advantage. Third, institutions matter. Anarchy does not permit insurance against consumption risk. With insurance, if agents can afford to trade at all they completely specialize and enjoy a certain consumption bundle. Consumption would be somewhere on the locus of tangencies of specialized budget lines above $\mathrm{A}$ and below $\mathrm{E}$, since 
the certainty equivalent price $p / \pi$ would have to incorporate the insurance premium. ${ }^{1}$ Fourth, the fixed cost of trade lowers the utility associated with trade, which may then not dominate autarky.

\section{International Trade and the Equilibrium Price}

The previous analysis set out the individual trader's decision as an implicit function of the international relative price of the traded goods, $p$. Now we determine the equilibrium $p$, conditional on $\pi$ and on the allocation of labor to production and predation. To build intuition for what follows, in this partial equilibrium setting we note conditions under which there exists no $p$ consistent with a trading equilibrium, shown here by parametrically driving $\pi$ lower until it destroys trade. In the full general equilibrium model, the levels of $\pi$ and of predatory and productive labor are endogenously determined along with $p$, and we drive $\pi$ down by changing the primitive parameters of the model, but the mechanism which destroys trade is similar.

An asterisk designates the foreign economy. It is convenient to work with the comparative labor productivity for each country's import good. For the foreign economy, $\alpha^{*}$ is the opportunity cost of good 2 . Whether predation exists or not, $\alpha>p>1 / \alpha^{*}$, where the strong inequality is due to the requirement that the fixed cost of trade must be covered.

The international equilibrium of the two country version of the model is determined by the market-clearing condition for the home country's imported good.

$$
\left(N-N^{P}\right) m_{1}(p, \pi ; 1-\bar{l}, \alpha)+\left(N^{*}-N^{* P}\right) m_{1}^{*}\left(p, \pi ; 1-\bar{l}^{*}, \alpha^{*}\right)=0 .
$$

Here $m_{1}$ denotes per producer excess demand for good 1 in the home country while $m_{1}^{*}$ denotes the per producer excess demand for good 1 in the foreign country. The per producer excess demands are scaled up by the number of

\footnotetext{
${ }^{1}$ This solution obtains in anarchy if each agent's trade is (implausibly) divisible into many independent trips to market while paying only one fixed defense cost.
} 
nonpredatory agents in each country, that is, by the total number of agents $N$ or $N^{*}$ less the number of agents from each country who enter predation, denoted with a superscript $P$. We assume here a complete separation between legitimate trade and the thieves' market in which captured goods are exchanged.

Analysis of the existence, uniqueness and stability of equilibrium in this model follows standard lines assuming the import demand functions are downward sloping (see Proposition 1(b)). Equilibrium need not be unique, since supply curves can bend backward. The sole question of existence arises from the effect of lower $\pi$ in reducing and eventually eliminating the range of potential equilibrium prices.

Consider the incipient autarky price at which the home country is just barely willing to trade. By (3.3) and (3.5) evaluated at $m_{1}=m_{2}=0$, $u_{1}\left(y_{1}, y_{2}\right) / u_{2}\left(y_{1}, y_{2}\right)=\alpha=\pi / p^{a} \Rightarrow p^{a}=\pi \alpha$. For the foreign economy, the incipient autarky price is similarly defined by $1 / p^{* a}=\pi \alpha^{*}$, or $p^{* a}=1 / \pi \alpha^{*}$. Solving the two equations simultaneously, the critical value of $\pi$ which eliminates the range of trading equilibria is: $\bar{\pi}=\left(\alpha \alpha^{*}\right)^{-1 / 2}$. A necessary condition for trade is that $\pi$ exceed $\left(\alpha \alpha^{*}\right)^{-1 / 2}$. This demonstrates the significance of the arbitrage margin $\alpha \alpha^{*}-1$ to the existence of trade. At an arbitrage margin of $44 \%$ the probability of successful exchange must exceed $83.3 \%$ to permit trade; at the larger arbitrage margin of $300 \%$, which we will use in later simulations, trade can exist only if the probability of successful exchange exceeds $50 \%$.

Figure 5 illustrates. The equilibrium at $\mathrm{E}$ permits trade according to comparative advantage, and mutual benefit despite some predation. With lower values of $\pi$, the range of prices between $\pi \alpha$ and $1 / \pi \alpha^{*}$ shrinks and eventually disappears, destroying all trade. For fixed $\pi$, reductions in the arbitrage margin similarly reduce trade. The need to cover the fixed costs of trade imposes still tighter limits on the range of trading equilibrium prices. 


\section{Figure 5: Trade Equilibrium and Security}

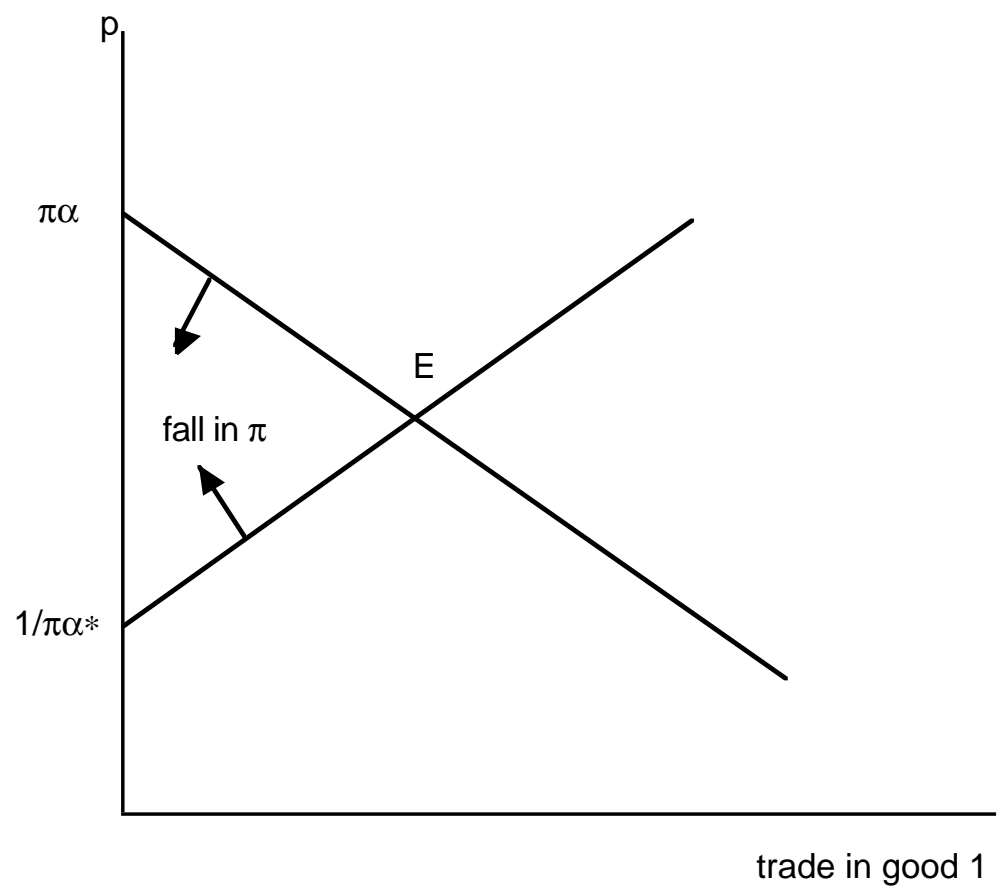

Summarizing the implications:

Proposition 2: For $\pi \leq\left(\alpha \alpha^{*}\right)^{-1 / 2}$, autarky prevails.

Proposition 2 shows that even leaving aside the fixed cost of trading $\bar{l}$, when traders are faced with exogenous predation, the market may not find a price at which voluntary exchange will occur. To enable trade either the probability of successful exchange must be quite high or the arbitrage margin must be quite high. Finally, we note that Proposition 2 extends to non-Ricardian production models: $\alpha$ and $\alpha^{*}$ simply refer to the autarky relative price of the incipiently importable good.

The diagrammatic analysis links our model to the familiar iceberg melting transactions costs, with 1- $\pi$ equal to the melting rate. The key differences are that in our model (i) the melting rate is endogenous, and (ii) away from the autarky point, our model differs by embodying behavior 
modified by the consumption risk due to predation.

\section{Predation and the Terms of Trade}

By application of standard comparative static methods to (3.6), $d p / d \pi$ has the sign of $m_{1 \pi}-\frac{1}{p} m_{2 \pi}^{*} \frac{N^{*}-N^{* P}}{N-N^{P}}$. The condition $u_{12}>0$ is sufficient but not necessary to guarantee that $m_{1 \pi}>0$, by Proposition 1 . When $m_{1 \pi}=m_{2 \pi}^{*} / p$, a natural benchmark case, lowering $\pi$ has the effect of improving the terms of trade of the larger country. In Figure 5, the excess demand function of the larger country shifts to the left by more.

Proposition 3: Lower probability of successful exchange improves the terms of trade of the larger country if the asymmetry of country size dominates other asymmetries in the case of weak Pareto complements.

For more intuition we refer to the Cobb-Douglas form used in our simulations. The parametric expenditure share for good 1 (the home country import) is denoted by $\gamma$. The benchmark result holds in the symmetric CobbDouglas case of $\alpha=\alpha *$ and $\gamma=1 / 2$ (see the Appendix). However, the prediction of an improvement in terms of trade for the larger country as $\pi$ falls also holds for asymmetric parameters in the Cobb-Douglas case if the asymmetry in country size is sufficiently great.

Under the condition of Proposition 3, the impact of decreased security on the welfare of producers in the larger country is ambiguous. In contrast, producers in the smaller country lose both from increased insecurity directly and from a terms of trade deterioration. The analysis suggests that producers in the two countries may have opposing interests in security arrangements when terms of trade effects are powerful. To complete the welfare analysis of security improvement requires simulation, as the welfare of producers 
changes according to the magnitudes of $\pi$ and $d p / d \pi$, both of which are deeply nonlinear functions of the parameters. We will return to the welfare analysis after developing the full model.

\section{Production and Trade with Endogenous Predation}

The previous section analyzed production, trade, and the terms of trade, taking the number of predators as fixed. Here we move to the full model, in which the number of predators and the probability of eluding capture are also endogenously determined.

\section{The Pay-off to Predation}

Predation pays by seizing shipments which can be consumed directly by those who capture them or exchanged in a thieves' market. The assumed separation of legal and illegal exchange simplifies the structure and affects the model only inessentially, since prices in the two markets are closely related in any case. ${ }^{2}$ The relative price of good 1 on the thieves' market $p^{P}$, is given by the marginal rate of substitution between the goods, which depends on the availability of each good in the thieves' market.

It is convenient to simplify by restricting tastes to be homothetic, so that the marginal rate of substitution depends only on the ratio of the quantities consumed of the two goods. The aggregate prize vector is $\left[(1-\pi) M_{1},(1-\pi) M_{2}^{*}\right]$ where $M_{i} \equiv\left(N-N^{P}\right) m_{i}$ denotes the aggregate quantity of home excess demand for good $i$. The ratio of goods available for thieves' consumption is thus $M_{1} / M_{2}^{*}=-M_{1} / M_{2}=p$, where the last step follows from the balanced trade constraint $p M_{1}=-M_{2}$. Then the thieves' market relative price is given by $p^{P}=v(p)$, where $v(\cdot)$ is the marginal rate of substitution. The

\footnotetext{
${ }^{2}$ Alternatively, we could assume that stolen goods find their way into legitimate commerce again, the appropriate setup when the household is treated as an integrated producing and predating agent. Allowing some members of the household to enter banditry complicates the notation but adds nothing essential to the analysis.
} 
aggregate value to thieves of the stolen goods is $(1-\pi)\left(p^{P} M_{1}-M_{2}\right)=(1-\pi)\left(p^{P}+p\right) M_{1}$. The expected income of each predator is then:

$$
z^{P}=(1-\pi)(v(p)+p) m_{1}(p, \pi ; 1-\bar{l}, \alpha)\left(\frac{N-N^{P}}{N^{P}+N^{* P}}\right) \cdot^{3}
$$

Further restricting the utility function to homogeneity of degree one imposes risk neutrality. This structure avoids the need to specify the detailed states of bandit income; only the mean matters. In this case, the indirect utility function is linear in income and the expected predator indirect utility function is:

$$
v^{P}=\phi(p, \pi ; 1-\bar{l}, \alpha)\left(\frac{N-N^{P}}{N^{P}+N^{* P}}\right)
$$

where $\phi(p, \pi ; 1-\bar{l}, \alpha) \equiv(1-\pi)(v(p)+p) m_{1}(p, \pi ; 1-\bar{l}, \alpha) / c(v(p), 1)$ and $c(v(p), 1)$ is the true cost of living index for the homogeneous of degree one utility function. See the Appendix for explicit closed form solutions for the trade and predator indirect utility functions for the Cobb-Douglas case.

\section{The Probability of Safe Shipment}

The probability of a safe shipment reflects the shippers' random encounters with predators as the former evade and the latter seek.

We assume that shipments originate in a diffuse region and go to a market point for exchange. Predators and prey spread themselves evenly on the approaches. It is quite reasonable to assume that the probability of evasion is a decreasing function of the ratio of predators to prey. We simplify the round trip shipment success rate to the logistic functional form which has been widely used in the previous predation literature:

\footnotetext{
${ }^{3}$ This specification is equivalent to pooled shares in banditry, where the aggregate proportion of goods stolen is certain and all individual risk is removed. With income-risk neutral bandits, as assumed in the Cobb-Douglas utility function, such pooling is irrelevant as the agent is indifferent between the expected per capita income with certainty and the uncertain stream with the same expected value. We prefer the individual uncertain return interpretation, as risk pooling presumes coordination.
} 


$$
\tilde{\pi}=\frac{1}{1+\theta \frac{N^{P}+N^{* P}}{\bar{l}\left(N+N^{*}-N^{P}-N^{* P}\right)}} .
$$

The parameter $\theta / \bar{l}$ captures the relative efficiency of offensive and evasive activity. With equal numbers and equal effectiveness $(\theta / \bar{l}=1)$, half of all exchanges would be successfully completed.

Our simple structure for the individual trader's allocation of labor to start up trade costs ensures that all shippers will devote exactly $\bar{l}$ to evasive capacity, bandits will attack shipments randomly, and the probability of loss will be the same in every case. This is a strong but harmless simplifying assumption for our research into the likelihood of autarky and the market channels through which predation and trade interact. ${ }^{4}$

\section{Equilibria with Endogenous Predation}

With the trade and predator indirect utility functions in hand, we fill out the description of Nash equilibria suggested in Section 2 of this paper. We turn first to the characterization of what we called there an "insecure" Nash equilibrium in which trade coexists with theft.

Predation is an international free entry activity. Aggregate predatory labor is the total number of bandits drawn from the two countries:

(4.4) $N^{P}+N^{* P}$.

Aggregate defensive labor is:

$$
\bar{l}\left(N+N^{*}-N^{P}-N^{* P}\right) .
$$

Domestic entry into predation requires that:

(4.6) $v^{P}=v^{T}>v^{A}$.

Foreign agents will engage in predation if:

$$
v^{P}=v^{* T} \geq v^{* A} \text {. }
$$

Usually, all the bandits will be supplied by the poorer country, the one with

\footnotetext{
${ }^{4}$ In contrast, the predation literature has been interested in precisely the interaction of defensive effort on the opposing offensive effort and on the various externalities generated by defensive effort of any one agent.
} 
lower welfare for the representative producer. For a small range of parameter values both equalities can hold, implying entry into banditry by both countries. ${ }^{5}$ We restrict attention to the more general cases of unequal utilities, based on our motivation to understand incentives in a world where rich and poor countries interact in trade and predation.

Inserting (4.2) into (4.6) and (4.7) and inverting, if $v^{P}=v^{* T}<v^{T}$ and a trading equilibrium exists, then:

$$
N^{* P}=\frac{\phi(p, \pi ; 1-\bar{l}, \alpha)}{v^{* T}} N, N^{P}=0 .
$$

If all predators come from the home country $\left(v^{P}=v^{T}<v^{*}\right)$, then:

$$
N^{P}=\frac{\phi(p, \pi ; 1-\bar{l}, \alpha)}{\phi(p, \pi ; 1-\bar{l}, \alpha)+v^{T}} N, N^{* P}=0
$$

In equilibrium, the probability of successful exchange which is realized, $\tilde{\pi}$, must be equal to the anticipated $\pi$ on which forward-looking agents based their calculations:

$$
\pi=\tilde{\pi}=\frac{1}{1+\theta \frac{N^{P}+N^{* P}}{\bar{l}\left(N+N^{*}-N^{P}-N^{* P}\right)} .}
$$

The interior equilibrium with insecure trade is the value of $\left(p, N^{P}, N^{* P}\right)$ which satisfies (4.8) and the exchange equilibrium condition (3.6) when the right hand side of (4.9) is substituted for $\pi$ in all expressions.

Interior equilibrium need not exist. Unfortunately, analytic methods are not able to reveal much about when it does. We therefore describe special cases - for which the intuitions seem likely to apply regardless of the details of functional form -- and then turn to simulation of the Cobb-Douglas model.

\footnotetext{
${ }^{5}$ The case where utilities are equal between the two countries and both supply predators is not a knife edge equilibrium. We are indebted to a referee for showing us this. The intuition is that entry into predation plays a role somewhat like migration would in equalizing utilities. We have not focused on such an equilibrium, since our interest is to explore the more interesting equilibria where one economy could be immiserized.
} 
Suppose that $\theta / \bar{l}$ is low. Secure equilibria with trade and no predation result when $\theta / \bar{l}$ is low enough to deter entry into banditry and a Ricardian complete specialization solution generates mutual gains from trade sufficient to pay for the fixed cost of defense.

The most interesting and complex class of equilibria are the interior solutions or insecure equilibria - labor is allocated to both defense and predation and there is incompletely specialized production with trade. Interior solutions give rise to a rich set of comparative statics which cannot be derived as special cases of previously known results. We turn to simulation to show these effects, using the Cobb-Douglas specification.

\section{Simulated Equilibria and Comparative Statics}

Simulations show that, under anarchy, trading equilibria can be supported only over a small subset of the parameter space. They also confirm that changes in the technology of predation have a non-monotonic impact on producer welfare in one of the two countries. The possibility of "immiserizing security" in turn can lead to the paradox of trade-creating predation. We argue that our inferences are robust with respect to generalizations of technology and preferences.

\section{Emergence of Autarkic, Secure, and Insecure Equilibria}

We have simulated the Cobb-Douglas model (see Appendix) with $\alpha=\alpha^{*}=2$, so that autarky price ratios differ by a factor of 4 . By Proposition 2, this arbitrage margin implies autarky if the probability of successful shipment is less than $1 / 2$. The foreign country is both larger and poorer (in an interior equilibrium $v^{* P}=v^{* T}<v^{T}$ ), with $\mathrm{N}=1000, \mathrm{~N}^{*}=1500$, and $\gamma=.45$. Holding relative country size and the autarky price ratios constant while varying $\bar{l}$ and $\theta$, we repeatedly solved simultaneously the Cobb-Douglas forms of the international market-clearing condition (3.6) and the predatory labor supply 
equations (4.8), using the solutions to trace changes in the equilibrium terms of trade $p$, the security of trade $\pi$, the gains from trade, and the volume of trade.

Figure 6 plots the $(\bar{l}, \theta)$ pairs for which a trading equilibrium exists. Squares denote parameters supporting secure equilibria; triangles denote insecure equilibria. The fixed cost of trade, $\bar{l}$, ranges from $0.25 \%$ to $8 \%$ of the trader's labor endowment. The relative effectiveness of predatory labor, $\theta$, ranges from 0 to 0.2 . No trading equilibria were found with $\theta>.2$ or $\bar{l}>8 \%$.

\section{Figure 6. Parameters Supporting Equilibria with Trade}

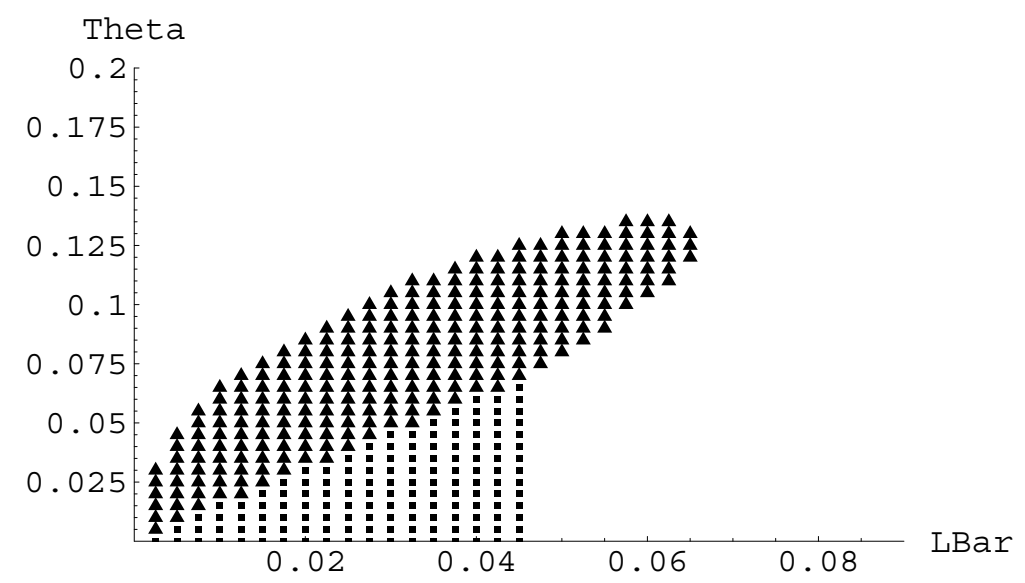

Note the small range of parameters which support trading equilibria. It is no surprise that trade can be choked off by increases in the fixed start-up $\operatorname{costs}, \bar{l}$, even if predatory labor is completely ineffective $(\theta=0)$. However, we were surprised by the huge impact of endogenously generated insecurity on the system's ability to sustain trade when fixed start-up costs are low, and we explored the robustness of this result with respect to changes in the other exogenous parameters. Eliminating the terms-of-trade effect associated with country size by equating populations $\left(N=N^{*}\right)$ expanded the scope for trade, as expected, but only to $6.5 \%$ of the space bounded by $.01 \leq \bar{l} \leq 1$ and $0 \leq \theta \leq 1$. 
Increasing the arbitrage margin to an outlandish $1500 \%$ by setting $\alpha=\alpha^{*}=4$ still generated trading equilibria in only $14 \%$ of that parameter space.

Implication 4: In the Ricardian Cobb-Douglas model, anarchy implies autarky for most parameter values.

The "overhang" in Figure 6 points to another surprise: the ambiguous role of improvements in predatory technology, $\theta$, for given $\bar{l}$. Beyond some point, enhancement of the technology of predation will choke off trade even when start-up costs of trade are low. Before that maximum $\theta$ is reached, however, improvements in predatory technology may actually encourage trade. For a range of fixed costs around $6 \%$ of labor, there is no trade for perfectly secure technologies (i.e., where $\theta=0$ ), because the foreign country's gains from trade do not cover the fixed costs. As $\theta$ rises, however, eventually a region is reached in which an insecure trading equilibrium exists.

This "paradox of trade-creating predation" is the other side of the "immiserizing security effect" for the large poor country. As will be shown in the next section, there is a range over which the terms of trade of the poorer country improve as insecurity increases. For $\bar{l}=.06$, the enhancement of the gains from trade of the poorer country as $\theta$ approaches .1 permits producers in that country to cover the fixed start-up costs of trade. Both countries then emerge from autarky into an insecure trading equilibrium, and, paradoxically, both countries are made better off by reductions in security which move from the system from "under the overhang" into the equilibrium set.

Anarchy does not permit coordination of predators or shippers. However, it is interesting to note that where predatory effort is relatively effective (say, $\theta=.1$ ), coordination which could raise evasive effort (say, from $\bar{l}=.01$ to $\bar{l}=.03$ ) would permit trade to emerge. Figure 6 also implies some interesting interactions between predation and evasive effort: as the evasive 
effort rises, so does the minimum $\theta$ necessary to coax anyone into predation, as does the maximum $\theta$ compatible with trade.

Uniqueness of equilibrium conditional on being in the interior is too difficult to prove analytically. Nevertheless, all interior equilibria we have found appear to be unique because grid searches with varying starting values failed to turn up any others.

\section{Simulated Comparative Statics}

As changes in $\theta$ and $\bar{l}$ shift the system from one trading equilibrium to another, they also change the terms of trade, the security of trade, and the gains from trade. We now consider the properties of these changes, holding relative country size and the Cobb-Douglas taste parameter at levels which reveal the possibility of immiserizing security. ${ }^{6}$ The parameters used are those described above: $\alpha=\alpha^{*}=2, N=1000, N^{*}=1500$, and $\gamma=.45$.

In these simulations there is a straightforward link between changes in $\theta$ and $\bar{l}$, changes in security, and changes in the terms of trade. The probability of successful shipment is an endogenous variable, deeply nonlinear with respect to the parameters. However, in these simulations, equilibrium $\pi$ is always non-increasing in $\theta$ and non-decreasing in $\bar{l}$. Moreover, as the security of a trading equilibrium increases, the terms of trade of the larger, poorer country deteriorate.

The possibility of immiserizing security arises as follows. Predators are drawn exclusively from the country with lower producer welfare. As the effectiveness of predatory labor decreases, some of that country's workers will migrate out of predation and into production. The endogenous labor reallocation lowers the relative price of that country's exported good and the welfare of those who supply it. Moreover, if that country is also the larger of the two, this "migration" terms of trade effect is reinforced by the "large 
country" effect of Proposition 3. The deterioration in the terms of trade can dominate the positive impact on welfare of increased trade volumes, so that increased security implies lower welfare.

\section{Fig 7. Foreign Gains from Trade as Effectiveness of Predatory Labor Rises}

$$
(\bar{l}=.05)
$$

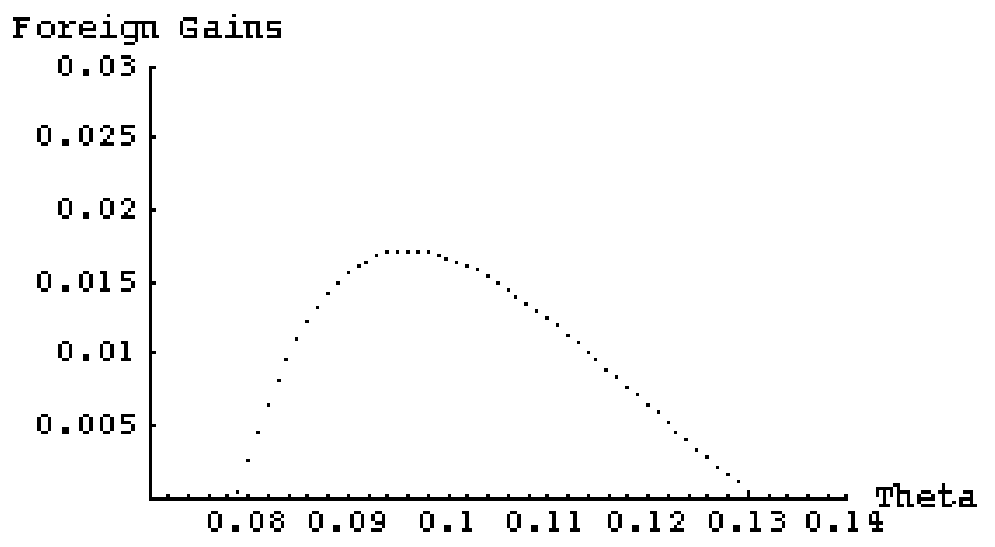

The overall effect is illustrated in Figure 7, which also sheds light on the "overhang" shown in Figure 6. We set $\bar{l}=.05$ and raised $\theta$ from .05 to .15 in increments of .001, then solved for the equilibrium values of $p$ and $\pi$. Using those values, we solved for the foreign gains from trade in equilibrium (the percentage increase in utility relative to autarky levels). The foreign country gains nothing from trade when $\theta$ is less than .08 , but as the effectiveness of predatory labor continues to rise, foreign welfare with insecure trade rises above autarky welfare. The welfare of foreign producers rises as security declines, because some foreign agents are drawn out of production and into predation, and the price offered for the foreign export on the world market rises. As $\theta$ approaches .13, on the other hand, insecurityassociated costs choke off the gains from trade once again. This is why, in Figure 6 , if one traces a vertical line upward at $\bar{l}=.05$, one finds that trade emerges in equilibrium only for $.8 \leq \theta \leq .13$. In a world without predation, the foreign country would not trade; for some worlds with predation, it would.

\footnotetext{
${ }^{6}$ As with immiserizing growth, the ability to tax trade removes immiserizing security.
} 
Note in passing that the supply of predators is infinitely elastic at the level of utility enjoyed by producers in the poorer country, so that the welfare enjoyed by foreign producers and predators will rise and fall together.

The home country's gains from trade over the same range, with $\bar{l}=.05$ and $.8 \leq \theta \leq .13$ are shown in Figure 8. Over the range of trading equilibria, home gains from trade diminish monotonically as the effectiveness of predatory labor rises. However, the home country still gains from trade in any of these insecure trading equilibria. Both countries are better off in an insecure equilibrium than they would be if potential trade were perfectly secure - because with $\bar{l}=.05$ perfectly secure trade is not associated with gains for the foreign country, and the system collapses to autarky. In some sense, by paying a higher price for imports under insecure trade, the home country brings the relatively less favored foreign country into the world market. Under these circumstances, predation creates trade.

Fig 8. Home Gains from Trade as Effectiveness of Predatory Labor Rises

$$
(\bar{l}=.05)
$$

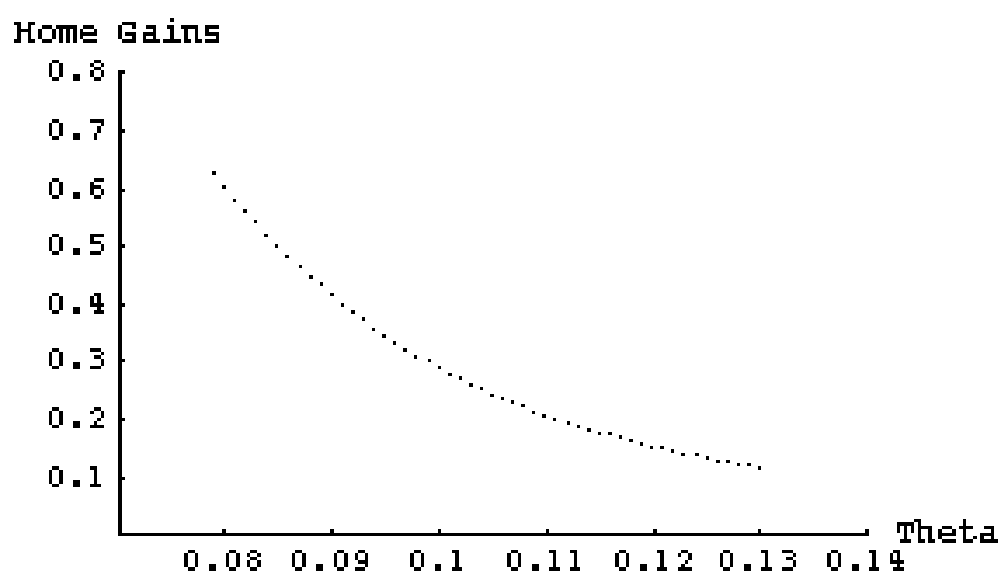

Summarizing these effects: 
Implication 5: In the Ricardian Cobb-Douglas model, there exist parameter values for which improvements in security via greater evasive effort or better technology of evasion are immiserizing for large poor countries.

It is worth emphasizing that immiserization is not connected with inferiority or special conditions on backward bending export supply; it comes through the direct effect of security on the terms of trade and the indirect effect changing relative country size through entry or exit from banditry.

\section{Robustness of Simulation Results}

Our conclusions about the shape and relative magnitude of the predation/evasion parameter space which supports trade are model-specific and dependent on the values of $\alpha, \alpha^{*}$ and $N / N^{*}$. Nevertheless, we argue that the conclusions are robust to changes in the specification of preferences and production technology. (i) Increases in the elasticity of substitution in consumption (equal to one above) will raise the volume of trade, while (ii) decreases in the elasticity of transformation in production (infinite above) will lower the volume of trade. The net effect of changes to more realistic cases is likely to be trade-reducing on balance. (iii) Risk aversion (in the sense of concave transformations of utility functions) is likely to shrink trade and also to shrink predation, with a net effect which is ambiguous but probably small.

The effect of changes in the specification of predation is less certain. Altering the functional form of the success rate from the logistic to some other cumulative density function of the limit value of the predator to prey ratio $\left(N^{P}+N^{* P}\right) / \bar{l}\left(N+N^{*}-N^{P}-N^{* P}\right)$ seems unlikely to change the conclusions. Switching to a multi-factor model of production and predation 
opens up more possibilities, including one in which the larger, richer country may tend to benefit from insecurity.

\section{Conclusion}

This paper focuses on the historically important destruction of trade by piracy. Theft is also a particularly clean way of modeling the impact of endogenous transactions costs on trade. Our general equilibrium model with endogenous predation sheds light on a particularly provocative episode in economic history, the collapse of the trade on which "all of European life ... could be said to have depended" (Wallerstein, previously cited). Yet the model is of more than historical interest; we believe it to be applicable not only when shipments are literally hijacked but also when they are whittled away by the demands of corrupt officials.

Under anarchy, that is, without coordination of predators or prey, trade exists only for a narrow range of technological parameters which interact in the intuitive ways explored in this paper. Shifts in these parameters can cause a dramatic collapse from a secure trading equilibrium to autarky. These considerations underscore the importance of institutions which foster common defense or which organize, and perhaps restrict, crime.

Security is shown to have significant terms of trade effects, amplified by the migration of labor into or out of production. This can lead larger, poorer

\footnotetext{
${ }^{7}$ In the Heckscher-Ohlin model we can sketch one plausible scenario. Assume that ex ante identical agents bring their per capita share of capital with them into banditry. We have to assume some sort of cooperation to get both factors their competitive factor reward in banditry. If the factor intensity of banditry lies between those of the two goods, for some factor endowments there will be bandits from both countries in equilibrium. Improvements in security will result in relative endowments being pushed further apart, so trade volume is more sensitive to security than in the Ricardian model. The possibility of immiserizing security in the larger, poorer country will be reduced, as both countries experience increases in their endowments which are trade creating. Indeed, it seems possible that producers in the smaller, richer country could prefer less security. This result will be even more likely if predation is the most capital intensive industry, as in this case the rich country has a comparative advantage in it. Immiserizing security will certainly be possible if the richer country is larger. In contrast, if predation is the least capital intensive industry, we return to the Ricardian result that predators come from the poorer country. We regard the latter specification as more plausible for
} 
countries to lose from improvements in the security of international exchange. Under some circumstances, immiserization effects can lead to the paradox of trade-creating predation. Immiserizing security suggests a potential for international conflict due to opposing national interests. It is natural, therefore, to investigate noncooperative approaches to the provision of international security. We plan to do so in future research.

banditry, but for some problems (e.g., intellectual property rights) it may be useful to think of predation as capital intensive. 


\section{REFERENCES}

Anderson, James, and Douglas Marcouiller (forthcoming), "Insecurity and the Pattern of Trade," The Review of Economics and Statistics.

Anderton, Charles H., Roxanne Anderton, and John Carter (1999), "Economic Activity in the Shadow of Conflict," Economic Inquiry 37:1, January, pp.166-179.

Barrett, Ward (1990), "World Bullion Flows," in The Rise of Merchant Empires: Long-Distance Trade in the Early Modern World 1350-1750, James Tracy, ed., Cambridge: Cambridge University Press, pp. 224-254.

Chaunu, Huguette, and Pierre Chaunu (1956), Séville et l'Atlantique (15041650) , Paris: S.E.V.P.E.N.

Deardorff, Alan (2001), "Local Comparative Advantage: Trade Costs and the Pattern of Trade," mimeo.

Grossman, Herschel and Minseong Kim (1995), "Swords or Ploughshares: a Theory of the Security of Claims to Property," Journal of Political Economy 103, 1275-1288.

Haring, C.H. (1918), Trade and Navigation between Spain and the Indies in the Time of the Hapsburgs, Cambridge, MA: Harvard University Press.

Hummels, David (2001), “Time as a Trade Barrier," mimeo, July.

Lynch, John (1969), Spain under the Hapsburgs, Vol. II: Spain and America 1598-1700, New York: Oxford University Press.

MacLeod, Murdo (1984), "Spain and America: The Atlantic Trade 1492-1720," in The Cambridge History of Latin America, Vol. I: Colonial Latin America, Leslie Bethell, ed., Cambridge: Cambridge University Press, pp. 342-388.

Marcouiller, Douglas (2001) “Hijacking, Hold-up, and International Trade, mimeo, October.

Mechner, Emily (1997) "Pirates and Politics: Monopoly and Moral Hazard in the Spanish West Indies Trade," mimeo, November 1997.

Phillips, Carla (1990), "The Growth and Composition of Trade in the Iberian Empires 1450-1750," in The Rise of Merchant Empires, op.cit., pp. 34101. 
Rauch, James E. (1999), “Networks Versus Markets in International Trade," Journal of International Economics 48:1, June, pp. 7-35.

Rauch, James E. and Vitor Trindade (1999), "Ethnic Chinese Networks in International Trade," NBER Working Paper No. 7189, June.

Rodrik, Dani (2000) "How Far Will International Economic Integration Go?" Journal of Economic Perspectives 14:1, 177-186, Winter.

Skaperdas, Stergios (1992), "Cooperation, Conflict and Power in the Absence of Property Rights", American Economic Review, 82, 720-39, September.

Skaperdas, Stergios and Constantinos Syropoulos (1996), "Competitive Trade with Conflict," in Michelle Garfinkel and Stergios Skaperdas (eds.) The Political Economy of Conflict and Appropriation, Cambridge: Cambridge University Press.

Skaperdas, Stergios and Constantinos Syropoulos (1997), "Insecure Property and the Stability of Exchange," mimeo.

Skaperdas, Stergios and Constantinos Syropoulos (2001), “Guns, Butter, and Openness: On the Relationship Between Security and Trade," American Economic Review 91:2, May, pp. 353-357.

Trefler, Daniel (1995), "The Case of the Missing Trade and Other Mysteries", American Economic Review, 85, 1029-1046.

Veitia Linage, Joseph de (1672), Norte de la Contratación de las Indias Occidentales, republished in 1945, Buenos Aires: Comisión Argentina de Fomento Interamericano.

Wallerstein, Immanuel (1974), The Modern World-System: Capitalist Agriculture and the Origins of the European World-Economy in the Sixteenth Century, New York: Academic Press.

Ward, Christopher (1993), Imperial Panama: Commerce and Conflict in Isthmian America 1550-1800, Albuquerque: University of New Mexico Press.

Zahedieh, Nuala (1986), "Trade, Plunder, and Economic Development in Early English Jamaica, 1655-89," Economic History Review 39:2, pp. 205222. 


\section{TECHNICAL APPENDIX: Agents' Decisions in the Cobb-Douglas Case}

A closed form solution for production and trade obtains if we assume that utility is a Cobb-Douglas function of the consumption bundle: $u=x_{1}^{\gamma} x_{2}^{1-\gamma}$. Here, $x$ denotes consumption. With some judicious substitution, we obtain a closed form solution for the quantities in four steps.

First, we obtain a solution for the import relative share. The combination of the efficiency conditions (3.4) for trade and (3.5) for production implies:

$$
\frac{\pi u_{1}^{G}}{(1-\pi) u_{1}^{B}}=\frac{p}{\alpha-p} \text {. }
$$

For the Cobb-Douglas case this implies

$$
\frac{\pi\left(x_{2}^{G} / x_{1}^{G}\right)^{1-\gamma}}{(1-\pi)\left(x_{2}^{B} / x_{1}^{B}\right)^{1-\gamma}}=\frac{\pi}{1-\pi}\left(x_{1}^{B} / x_{1}^{G}\right)^{1-\gamma}=\frac{p}{\alpha-p} .
$$

Here, we have used the fact that $\mathrm{x}_{2}=\mathrm{y}_{2}+\mathrm{m}_{2}$ in each state. Now note that

$$
x_{1}^{B} / x_{1}^{G}=y_{1} /\left(y_{1}+m_{1}\right) \text {. }
$$

Solving this expression for the import relative share $m_{1} / y_{1}$ we obtain

$$
\frac{m_{1}}{y_{1}}=\left[\frac{(1-\pi) p}{\pi(\alpha-p)}\right]^{-1 /(1-\gamma)}-1 \equiv f(p, \pi, \alpha, \gamma) .
$$

This import share is undefined at $\pi=1$, as is appropriate since in that case the classic Ricardian model obtains and production will either be equal to zero or indeterminate. It is defined everywhere else, which means that with CobbDouglas preferences, complete specialization is never optimal in the presence of predation.

Second, we obtain the consumption ratio in the two states in terms of the import share and the production ratio. We substitute into the ratio of consumption in the two states using $m_{2}=-p m_{1}$ to solve in terms of $m_{1} / y_{1}$ and $y_{2} / y_{1}$.

$\frac{x_{1}^{B}}{x_{2}^{B}}=\frac{y_{1}}{y_{2}+m_{2}}=\frac{1}{y_{2} / y_{1}-p m_{1} / y_{1}}$ and

$$
\frac{x_{1}^{G}}{x_{2}^{G}}=\frac{y_{1}+m_{1}}{y_{2}+m_{2}}=\frac{1+m_{1} / y_{1}}{y_{2} / y_{1}-p m_{1} / y_{1}} \text {. }
$$

Third, we solve for the production ratio. Substituting the preceding expressions for the consumption ratios into the efficiency condition for imports and using $f(p)$ for the import share $m_{1} / y_{1}$ we obtain:

$$
\frac{\pi u_{1}^{G}}{\pi u_{2}^{G}+(1-\pi) u_{2}^{B}}=p=\frac{\pi \gamma\left[\frac{1+f(\cdot)}{y_{2} / y_{1}-p f(\cdot)}\right]^{\gamma-1}}{\pi(1-\gamma)\left[\frac{1+f(\cdot)}{y_{2} / y_{1}-p f(\cdot)}\right]^{\gamma}+(1-\pi)(1-\gamma)\left[\frac{1}{y_{2} / y_{1}-p f(\cdot)}\right]^{\gamma}} .
$$

This expression may be solved for $y_{2} / y_{1}$ to yield: 


$$
\begin{aligned}
\frac{y_{2}}{y_{1}} & =\frac{p\left\{\pi(1-\gamma)[1+f(\cdot)]^{\gamma}+(1-\pi)(1-\gamma)\right\}}{\pi \gamma[1+f(\cdot)]^{\gamma-1}}+p f(\cdot) \\
& =p \frac{1-\gamma}{\gamma}+p f \frac{1}{\gamma}+p \frac{1-\pi}{\pi} \frac{1-\gamma}{\gamma}(1+f)^{1-\gamma} \\
& =p \frac{f}{\gamma}+\alpha \frac{1-\gamma}{\gamma}=\frac{p f+\alpha}{\gamma}-\alpha .
\end{aligned}
$$

Finally, in combination with the full employment constraint $\alpha y_{1}+y_{2} \leq 1-\vec{l}$, the production ratio yields the closed form solution for $y_{1}, m_{1}, y_{2}, m_{2}$ as functions of the variables $p$ and $\pi$ and the parameter $\alpha$.

(A.2) $y_{1}=\frac{\gamma(1-\vec{l})}{p f(p, \pi, \alpha, \gamma)+\alpha}$.

Then in turn:

$$
\begin{aligned}
& m_{1}=\frac{\not f f(p, \pi, \alpha, \gamma)}{p f(p, \pi, \alpha, \gamma)+\alpha}(1-\vec{l}) \\
& y_{2}=(1-\vec{l})-\alpha \gamma \frac{(1-\vec{l})}{p f(p, \pi, \alpha, \gamma)+\alpha} \\
& m_{2}=-\gamma p f(p, \pi, \alpha, \gamma) \frac{(1-\vec{l})}{f(p, \pi, \alpha, \gamma)+\alpha}
\end{aligned}
$$

The Cobb-Douglas form of the trade indirect utility function $v^{T}$ is found by substituting the equilibrium values (A.2)-(A.5) into the utility function:

$$
v^{T}(p, \pi ; 1-\bar{l}, \alpha) \equiv\left\{\pi\left[\frac{1+f}{p f+\alpha}\right]^{\gamma}+(1-\pi)\left[\frac{1}{p f+\alpha}\right]^{\gamma}\right\}(1-\bar{l}) .
$$

In autarky, a home producer's utility depends solely on $\alpha$; in the CobbDouglas case autarky utility is given by $v^{A}(\alpha)=\alpha^{-\gamma}$.

Deriving the foreign economy's excess demand functions in the CobbDouglas case simply replicates the steps above, recognizing that the role of goods 1 and 2 is switched, and recognizing that the relative price of imports for the foreigner is $1 / p$ and that the marginal rate of transformation relevant to the steps above is that for the import good in terms of the export good. All properties are the same, mutatis mutandis. Similar steps characterize the utility of the foreign trader in the Cobb-Douglas case:

$$
v^{* T}\left(p, \pi, \alpha^{*}, 1-\bar{l}^{*}\right)=\left\{\pi\left[\frac{1+f^{*}}{f^{*} / p+\alpha^{*}}\right]^{1-\gamma}+(1-\pi)\left[\frac{1}{f^{*} / p+\alpha^{*}}\right]^{1-\gamma}\right\}\left(1-\bar{l}^{*}\right) .
$$

The foreign agent's autarky utility is $v^{* A}=\alpha^{*^{-(1-\gamma)}}$.

The predators' indirect utility function in the Cobb-Douglas case is derived as follows. First, the relative price of good 1 on the thieves' market (see Section 4) is: 


$$
p^{B}=\frac{\gamma}{1-\gamma} \frac{-M_{2}}{M_{1}}=\frac{\gamma}{1-\gamma} p
$$

and the utility associated with predation is:

$$
v^{P}=\left(p^{P}\right)^{-\gamma}(1-\pi) \frac{p^{P} M_{1}-M_{2}}{N^{P}+N^{*}}=\gamma^{-\gamma}\left(\frac{p}{1-\gamma}\right)^{1-\gamma}(1-\pi) m_{1}\left(\frac{N-N^{P}}{N^{P}+N^{* P}}\right),
$$

with the reduced form import demand function

$$
m_{1}=\frac{\gamma f(p, \pi, \alpha, \gamma)}{p f(p, \pi, \alpha, \gamma)+\alpha}(1-\bar{l}),
$$

where $f(\cdot) \equiv \frac{m_{1}}{y_{1}}=\left[\frac{(1-\pi) p}{\pi(\alpha-p)}\right]^{-1 /(1-\gamma)}-1$.

The above equations define the Cobb-Douglas version of the model. The properties of the full Cobb-Douglas model are explored in Section 5 of the paper through simulation. Closed form partial equilibrium comparative static results for the system (A.2)-(A.5) are available if we take $\pi$ to be an exogenous variable, as in Section 3 of the paper. It is immediate that a rise in "effective size" $(1-\vec{l})$ will raise trade volume, as is intuitive. We anticipate that a rise in $\pi$ will raise the level of trade $m_{1}$ and the degree of specialization measured by $\mathrm{y}_{2}$. A rise in $\alpha$ should also raise trade as it increases the gap between the autarky price ratio and the price available through trade.

First differentiate the import relative share function $f(p, \pi, \alpha)$.

$$
\begin{aligned}
& f(p, \pi, \alpha, \gamma) \equiv\left[\frac{p(1-\pi)}{(\alpha-p) \pi}\right]^{-1 /(1-\gamma)}-1, \text { hence } \\
& f_{p}=-\frac{1+f}{1-\gamma}[1 / p+1 /(\alpha-p)]<0 \\
& f_{\pi}=\frac{1+f}{1-\gamma}[1 / \pi+1 /(1-\pi)]>0 \\
& f_{\alpha}=\frac{1+f}{1-\gamma}[1 /(\alpha-p)]>0 .
\end{aligned}
$$

Now we are in a position to analyze the properties of the per capita import demand function $m_{1}(p, \pi, a)$. Differentiating (A.3) with respect to p:

$$
m_{1_{p}}=m_{1}\left[\frac{f_{p}}{f}\left(1-\frac{p f}{p f+\alpha}\right)-\frac{1}{p f+\alpha}\right]<0 .
$$

The negative sign follows from noting that the square bracket term is negative for positive imports. As for the response of $m_{1}$ to a rise in $\pi$, we can show that this is positive and approaches zero as complete specialization is approached:

$$
m_{1_{\pi}}=m_{1}\left(1-\frac{p}{p f+\alpha}\right) \frac{f_{\pi}}{f}>0
$$

